Anuario de la Facultad de Derecho. Universidad de Extremadura 35 (2019): 299-324

ISSN: 0213-988X - ISSN-e: 2695-7728

Doi: https://doi.org/10.17398/2695-7728.35.299

\title{
COMENTARIO PARCIAL A LA LEY DE CONTRATOS DE CRÉDITOS INMOBILIARIOS
}

\author{
PARTIAL COMMENTARY TO THE REAL ESTATE CREDIT \\ CONTRACT LAW
}

\author{
MARÍA SANDRA VELÁZQUEZ VIOQUE \\ Ilustre Colegio de Abogados de Cáceres
}

Recibido: 08/o6/2019 Aceptado: 18/o9/2019

\section{RESUMEN}

Se ha publicado en el BOE de 16 marzo la Ley 5/2019 reguladora de los contratos de crédito inmobiliario. Mediante esta ley, y con tres años de retraso, se transpone parcialmente la Directiva 2014/17/UE del Parlamento Europeo y del Consejo, de 4 de febrero de 2014, sobre los contratos de crédito celebrados con los consumidores para bienes inmuebles de uso residencial. El objeto de este artículo es poner de manifiesto alguna de las novedades más importantes que introduce respecto a los contratos que pretende regular.

Palabras clave: Contratos de créditos inmobiliarios, deber de transparencia, contenido contractual imperativo, hipoteca, Ficha Europea de Información Normalizada (FEIN).

\section{ABSTRACT}

It has been published in the BOE (March 16) Law 5/2019 regulating Real Estate Credit Contracts. By means of this law, and with three years of delay, Directive 2014/17 / EU of the European Parliament and of the Council, dated February 4,2014 , is partially transposed, Directive that regulates credit contracts celebrated with consumers related to real estate for residential use. The purpose 
of this article is to highlight some of the most important novelties that it introduces with respect to the contracts it intends to regulate.

Keywords: Real estate credit agreements, duty of transparency, imperative contractual content, mortgage, European Standardised Information Sheet (ESIS).

Sumario: 1. Ámbito de aplicación de la Ley: 1.1. Delimitación subjetiva; 1.2. Delimitación objetiva. 2. Procedimientos previos al otorgamiento del contrato: 2.1. Publicidad de los préstamos y deber de trasparencia; 2.2. Evaluación de la solvencia del prestatario; 2.3. Información precontractual personalizada y asesoramiento del notario; 2.4. La Ficha Europea de Información Normalizada (FEIN); 2.5. Tasación de los bienes inmuebles. 3. Contenido del contrato: 3.1. Las ventas vinculadas; 3.2. Préstamos en divisa extranjera; 3.3. Tipo de interés remuneratorio; 3.4. Amortización anticipada a voluntad del prestatario; 3.5. Vencimiento anticipado del préstamo por incumplimiento; 3.6. Interés de demora. 4. La subrogación en el préstamo. 5. Conclusiones.

\section{1. ÁMBITO DE APLICACIÓN DE LA LEY}

\subsection{DELIMITACIÓN SUBJETIVA}

Una de las cuestiones que en su momento más llamó la atención de la ley -transcurridos 5 años desde la Directiva y 3 desde el Anteproyecto es difícil que sorprenda su regulación-, fue la modificación-ampliación de su ámbito subjetivo, ya que el "consumidor" de la Directiva se transforma en el "prestatario" de la Ley, de forma que las medidas de protección que vamos a ver serán de aplicación a toda persona física que suscriba un contrato de crédito con unas determinadas condiciones, con independencia de que lo haga como particular o como empresario (la Exposición de Motivos hace referencia a los “autónomos”). Además, la protección se extiende al fiador o garante del prestatario $^{1}$ siempre que sea

\footnotetext{
1 Artículo 1. Objeto: Esta Ley tiene por objeto establecer determinadas normas de protección de las personas físicas que sean deudores, fiadores o garantes, de préstamos que estén garantizados mediante hipoteca u otro derecho real de garantía sobre bienes inmuebles de uso residencial o cuya finalidad sea adquirir o conservar derechos de propiedad sobre terrenos o inmuebles construidos o por construir.
} 
persona física, con independencia de que el prestatario sea una persona jurídica y de que el crédito/préstamo se solicite en el ámbito de su actividad empresarial.

Por otra parte, será de aplicación también a aquellos contratos de crédito que otorguen los consumidores -aquí parece que sí- cuando tengan por objeto el adquirir o mantener derechos de propiedad sobre inmueble o un terreno con o sin edificación (terrenos o inmuebles construidos o por construir /fincas o edificios construidos o por construir), sin requerir expresamente la constitución hipoteca sobre la misma ${ }^{2}$. No será requisito indispensable para la aplicación de las cautelas de la ley el otorgar una garantía inmobiliaria.

La condición de consumidor que parece exigir la Ley para ser aplicable a este segundo grupo de contratos es olvidada en otras ocasiones a lo largo de la misma. Ya en el artículo 4, que recoge las definiciones, entiende por prestatario, a efectos de la Ley "toda persona física que sea deudor de préstamos que estén garantizados mediante hipoteca sobre bienes inmuebles de uso residencial o cuya finalidad sea la adquisición o conservación de terrenos o inmuebles construidos o por construir”.

El prestamista será, obligatoriamente, un sujeto que se dedique a la actividad crediticia o a la intermediación en el crédito de forma profesional. A estos efectos "se entenderá que la actividad de concesión de préstamos hipotecarios se desarrolla con carácter profesional cuando el prestamista, sea persona física o jurídica, intervenga en el mercado de servicios financieros con carácter empresarial o profesional o, aun de forma

2 Ricardo Cabañas realiza la siguiente advertencia previa, en su estudio a la nueva Ley: "La Ley $5 / 2019$, de 15 de marzo, reguladora de los contratos de crédito inmobiliario, no es una Ley general sobre préstamo hipotecario, ni sobre préstamo con consumidores, sino sobre una modalidad específica de préstamo/crédito identificada como Contrato de Crédito Inmobiliario - CCI-, que no siempre contará con garantía hipotecaria. Con independencia de que sus DDAA y DDFF establezcan, en ocasiones, normas más generales o reformen leyes de ámbito superior y distinto, como la LH o la LEC, el núcleo duro de la regulación se centra en el CCI. Conviene tenerlo muy en cuenta para no pensar que algunas de sus disposiciones resuelven cuestiones referidas a todos los préstamos con hipoteca. Por eso es de gran importancia acotar de manera precisa el ámbito de aplicación de la LCCI, o determinar cuándo estamos ante un CCI, que es lo mismo", en Ricardo Cabanas Trejo, "La nueva Ley reguladora de los Contratos de Crédito Inmobiliario", Diario La Ley 9379 (2019): 1 
ocasional, con una finalidad exclusivamente inversora" (Art. 2.1 in fine). Por tanto, será de aplicación también a las entidades de crédito cuando los contratos suscritos se ajusten a lo estipulado en la ley. Por el contrario, no será de aplicación a la compra de inmueble que se financie ocasionalmente por el promotor mediante aplazamiento en el pago del precio con la garantía de una condición resolutoria, pues no se trata de un profesional del crédito ${ }^{3}$.

\subsection{DELIMITACIÓN OBJETIVA}

La Ley se aplica a aquellos contratos de préstamo o crédito en los cuales concurre una de las dos circunstancias siguientes:

a) Que en los mismos se constituya hipoteca o cualquier garantía real sobre un determinado inmueble cualificado en la Ley, un inmueble de uso residencial, entendiendo incluido en este concepto elementos tales como trasteros o garajes y cualesquiera otros que "sin constituir vivienda como tal cumplen una función doméstica” (art. 2.1. a). La Ley no exige que constituya vivienda habitual de quien lo grava, por lo que se admite que sea segunda vivienda. Incluso podrá ser de aplicación al préstamo empresarial con garantía hipotecaria sobre inmueble de uso residencial cuya explotación se el objeto del ejercicio profesional del prestatario (v.g. para su alquiler).

b) Que el contrato tenga como finalidad adquirir o conservar derechos de propiedad sobre terrenos o inmuebles construidos o por construir. Como hemos comentado, en este supuesto la Ley parece exigir la condición de consumidor -aunque en alguna ocasión la

3 Ricardo Cabanas Trejo, "Anotaciones de un notario perplejo al Anteproyecto de Ley Reguladora de los Contratos de Crédito Inmobiliario”, Diario La Ley 9047 (2017): 4. 
condición de consumidor "se cae" del articulado-, y no requiere constitución de garantía real sobre la finca ${ }^{4}$.

A pesar de concurrir alguna de las circunstancias arriba enunciadas, no será de aplicación la Ley si se dan alguno de los supuestos de exclusión ${ }^{5}$.

Por tanto, tendrá que hacerse una doble comprobación a los efectos de determinar la aplicabilidad de esta Ley al supuesto concreto.

\section{PROCEDIMIENTOS PREVIOS AL OTORGAMIENTO DEL CONTRATO}

Con objeto de que el prestatario sea correctamente informado de todos los asuntos que atañen al crédito, y que se cumplan las exigencias de transparencia que exige la ley, se regulan unos procedimientos específicos para ayudar a la formación de la voluntad del prestatario y a la resolución de concesión del préstamo por parte del prestamista.

4 "Esta segunda tipología de préstamo se define por las siguientes notas esenciales: (i) no es necesario que se constituya una garantía hipotecaria u otro derecho real sobre un bien inmueble de uso residencial; (ii) el prestatario, el fiador o el garante tiene que ser un consumidor; y (iii) el préstamo se tiene que destinar a la adquisición o conservación de derechos de propiedad sobre terrenos o inmuebles construidos o por construir de uso residencial", Antonio José Moya Fernández, Javier Villanueva Redondo y Javier Colino Sánchez-Ventura: "El Proyecto de Ley reguladora de los contratos de crédito inmobiliario", Actualidad Jurídica Uría Menéndez 48 (2018): 105, https://www.uria.com/documentos/publicaciones/5806/documento/foro_esp_05.pdf?id=7882

5 Son los siguientes:

a) concedidos por un empleador a sus empleados, a título accesorio y sin intereses o cuya Tasa Anual Equivalente sea inferior a la del mercado, y que no se ofrezcan al público en general,

b) concedidos sin intereses y sin ningún otro tipo de gastos, excepto los destinados a cubrir los costes directamente relacionados con la garantía del préstamo,

c) concedidos en forma de facilidad de descubierto y que tengan que reembolsarse en el plazo de un mes,

d) resultado de un acuerdo alcanzado ante un órgano jurisdiccional, arbitral, o en un procedimiento de conciliación o mediación,

e) relativos al pago aplazado, sin gastos, de una deuda existente, siempre que no se trate de contratos de préstamo garantizados por una hipoteca sobre bienes inmuebles de uso residencial, $o$

f) hipoteca inversa en que el prestamista:

(i) desembolsa un importe a tanto alzado o hace pagos periódicos u otras formas de desembolso crediticio a cambio de un importe derivado de la venta futura de un bien inmueble de uso residencial o de un derecho relativo a un bien inmueble de uso residencial, y

(ii) no persigue el reembolso del préstamo hasta que no se produzcan uno o varios de los acontecimientos previstos en la disposición adicional primera de la Ley 41/2007, de 7 de diciembre, salvo incumplimiento del prestatario de sus obligaciones contractuales que permita al prestamista la rescisión del contrato de préstamo. 
Los contratos objeto de la Ley no se caracterizan por ser objeto de negociación sino más bien al contrario, suelen estar integrados por cláusulas predispuestas. Por ello, la doctrina ha puesto de manifiesto la paradoja de "que en un contrato en el que falta la negociación, los tratos preliminares tomen ese carácter de complejidad y permanencia documental"6.

\subsection{PUBLICIDAD DE LOS PRÉSTAMOS Y DEBER DE TRANSPARENCIA}

La ley regula el contenido mínimo -información básica (Art. 6)- que debe constar en la publicidad de los préstamos inmobiliarios (destaca la necesidad de presentar los datos mediante ejemplos representativos o ilustrativos, criterios serán fijados en el Ministerio de Economía y Empresa), la obligación de dar publicidad a las condiciones generales de la contratación que incluyan como cláusulas de sus contratos (art. 7), para lo que se modifica la Ley 7/1998, de 13 de abril (DA 4 ${ }^{\mathrm{a}}$ ), y la forma de cálculo de la Tasa Anual Equivalente (T.A.E).

El deber de transparencia formal se concreta en la obligación de publicidad de las condiciones generales no sólo en el Registro de Condiciones Generales de la Contratación (RCGC), sino también en la página web del prestamista, si la tuviera. Ambas son obligatorias y no se excluyen entre sí. De no tener página web, deberá tener a disposición de los clientes las mismas y de forma gratuita en los establecimientos abiertos al público (art. 7).

El incumplimiento de esta obligación de publicidad impedirá, según la doctrina, "en todo caso, la inscripción en el Registro de la Propiedad de cláusulas favorables al prestamista...no publicadas en el RCGC ${ }^{7}$, además de proponer otros efectos ante el incumplimiento de la obligación

6 Carlos Balluguera Gómez, "Control de transparencia registral de la hipoteca, Registro de Condiciones Generales de la Contratación y Registro de la Propiedad”, en Especial Ley Reguladora de los Contratos de Crédito Inmobiliario (Las Rozas, Madrid: Wolters Kluwer, 2019), 2.

7 Vid. Balluguera, “Control...”, 8 ss. 
que no conllevan la nulidad del contrato, por entender que esta situación sólo favorecería al predisponente ${ }^{8}$.

Las DDFF $4^{\mathrm{a}}$ y $5^{\mathrm{a}}$ de la Ley también modifican el régimen de inscripción de las sentencias firmes dictadas en acciones colectivas o individuales por las que se declare la nulidad, cesación o retractación en la utilización de condiciones generales abusivas, siendo ahora obligatoria la inscripción de todas ellas en el RCGC. Para ello, se modifica el artículo 521.4 de la Ley de Enjuiciamiento Civil, estableciendo la inscripción de oficio por el órgano judicial. Por otra parte, estas medidas facilitan el cumplimento del deber de transparencia y su control.

$\mathrm{El}$ art. 8 regula las partidas de gastos que habrán de ser tenidas en cuenta para el cálculo de la T.A.E. ${ }^{9}$, que se complementa con el Anexo 2, que regula el procedimiento, con su fórmula matemática, y que ha pasado tal cual del Anexo 1 de la Directiva. La Ley hace especial hincapié en que tanto en la publicidad general como en la fase de información personalizada precontractual los prestamistas recojan qué gastos han sido incluidos en la TAE y cuáles otros no han sido incluidos en la misma, procurando que no haya desviación entre los gastos publicitados-comunicados al posible prestatario y los gastos que realmente van a ser asumidos,

8 "El incumplimiento de la obligación de inscripción por el prestamista de las condiciones generales de su hipoteca en el RCGC tiene efectos en el Registro de la Propiedad:

1. Si la falta de depósito es total, los préstamos hipotecarios concedidos por el prestamista no producirán efecto sino en perjuicio del predisponente, que sólo podrá reclamar la restitución del capital en los plazos estipulados, pero sin poder cobrar intereses ni otras cargas del contrato.

2. Si la falta de depósito es parcial, por omisión de una cláusula o divergencia en perjuicio de la persona consumidora, entre la cláusula depositada y el contenido contractual, en ese caso la cláusula divergente será inválida sin posibilidad de integración a favor del acreedor.

3. La falta de depósito total o parcial impide al acreedor poner en mora al deudor hasta tanto que cumpla con tal obligación.

4. Como la obligación de depósito es previa a la conclusión del contrato, por lo general será insubsanable, requiriendo su subsanación un nuevo otorgamiento con consentimiento del deudor. 5. La inscripción de sentencias de nulidad en el RCGC tiene un cierto efecto prejudicial en el Registro de la Propiedad que permite a las personas registradoras, denegar las cláusulas abusivas inscritas en el RCGC con el sólo argumento de citar el lugar de inscripción de la cláusula inválida en dicho Registro". (Balluguera, "Control...", 11).

9 Art. 4.14: "Tasa Anual Equivalente" (TAE): el coste total del préstamo para el prestatario, expresado como porcentaje anual del importe total del préstamo concedido, más los costes aparejados, si ha lugar, y que corresponde, sobre una base anual, al valor actual de todos los compromisos futuros o existentes, tales como disposiciones de fondos, reembolsos y gastos, convenidos por el prestamista y el prestatario. 
a efectos de saber realmente el coste total del producto a contratar. $\mathrm{Si}$ algún gasto no puede ser incluido por desconocerse previamente su entidad, se deberá hacer constar expresamente.

\subsection{EVALUACIÓN DE LA SOLVENCIA DEL PRESTATARIO}

El prestamista, que debe actuar de manera honesta, imparcial, transparente y profesional (art. 5), tiene la obligación de evaluar "en profundidad” la solvencia del potencial prestatario (art. 11), y prestará sus servicios o concederá el préstamo en función de la información obtenida sobre las circunstancias del prestatario, quien deber colaborar y facilitar tal información, sin prejuicio de la consulta a las bases de datos de solvencia patrimonial (art. 11.6).

En concreto, deberá tener en cuenta datos tales como la situación de empleo, los ingresos actuales y los previsibles a lo largo de la vida del préstamo, las propiedades (activos), el ahorro, los gastos fijos, las obligaciones previas del potencial prestatario y el nivel previsible de ingresos tras la jubilación, si el préstamo se extendiese más allá de la vida laboral. El valor de la garantía o su revalorización no pueden ser causa determinante de una evaluación positiva de la solvencia, salvo que el préstamo vaya a ser destinado a la construcción o renovación de la misma.

La doctrina ha puesto de manifiesto que la evaluación de la solvencia del solicitante es la actividad más importante de esta fase previa ${ }^{10}$. Asimismo, patentiza que el planteamiento tanto de la Directiva como de la Ley que la adapta se han quedado "cortos" por indefinición ${ }^{11}$ y que ésta última ha pasado por alto lo verdaderamente novedoso de la Directiva respecto a la obligación de evaluar la solvencia y es que ésta pasa de ser un medio de proteger a la entidad bancaria, en el ámbito de la ordenación

10 Miguel Díez De Los Ríos Flores, "La Ficha Europea del Crédito Hipotecario (FEIN)", en El préstamo hipotecario y el mercado de crédito en la Unión Europea, dir. por María De La Sierra Flores Doña (Madrid: Dykinson 2016), 387.

11 Matilde Cuena Casas, "Préstamo responsable y datos de solvencia patrimonial en la Ley Reguladora de los Contratos de Crédito Inmobiliario”, Actualidad Civil 9 (2019): 2. 
y supervisión bancaria, para transformarse en un medio de protección del prestatario frente al sobreendeudamiento.

Se ha desaprovechado, pues, la oportunidad de establecer datos objetivos (ratios) que hicieran controlable, de forma sencilla, el cumplimiento de esta obligación por parte de los prestamistas y, por otra parte, imponer sanciones ante su incumplimiento ${ }^{12}$, ya sea por investigación insuficiente ya sea por conceder el préstamo a pesar de la evaluación negativa. Se limita a indicar la ley que el prestamista sólo pondrá el préstamo a disposición del prestatario si el resultado de la evaluación de la solvencia indica que es "probable" que las obligaciones derivadas del contrato de préstamo se cumplan (Art. 11.5).

Una evaluación incorrecta de la solvencia del prestatario no puede ser causa de resolución, rescisión o modificación del préstamo salvo que el error provenga de una conducta dolosa del prestatario, lo que interpretado a contrario conlleva que sí pueda ser alegado en caso de ser imputable al mismo. Esencialmente podrá ser una medida de presión por parte del prestamista para modificar el préstamo so pena de solicitar su resolución o rescisión.

Los prestamistas deben contar con procedimientos propios dirigidos a realizar esta labor de evaluación de la solvencia del cliente, cuyo coste no pueden repercutir al prestatario (art. 11.2), si bien al referirse a la comisión de apertura -que se admite por la ley-, hace referencia a los "gastos de estudio, tramitación o concesión del préstamo" (art. 14.4).

Como en la Directiva se daba especial importancia al acceso de las entidades crediticias a los registros de solvencia a los efectos de poder evaluar convenientemente la situación patrimonial del posible prestatario, la Ley modifica la L. 44/2002, de 22 de noviembre, de medidas de Reforma del Sistema Financiero (BOE núm. 281, de 23 de noviembre de

12 Propone Matilde Cuena la pérdida del derecho de cobro de intereses ordinarios o de demora o la subordinación del crédito en el concurso como sanción por conceder el préstamo de manera irresponsable (Cuena, "Préstamo responsable...”, 10) 
2002), autorizado a todas las entidades de crédito y a los intermediarios el acceso a la Central de Información de Riesgos (CIR) ${ }^{13}$.

Si el préstamo es denegado como consecuencia de la consulta realizada a alguna base de datos o fichero de solvencia patrimonial, el prestamista deberá ponerlo en conocimiento del cliente y, en su caso, del fiador o avalista, y proporcionarle una copia de la consulta realizada, informándole del nombre y representante de la base consultada y de sus derechos a acceder y rectificar dichos datos.

Por último, procederá realizar una nueva evaluación de la solvencia cuando se pretenda aumentar el capital prestado con posterioridad, mediante novación del préstamo.

\subsection{INFORMACIÓN PRECONTRACTUAL PERSONALIZADA Y ASESORA-} MIENTO DEL NOTARIO

Aparte de la obligación del prestamista, intermediario o sus representantes de facilitar información general sobre sus contratos de créditos a los potenciales prestatarios (art. 9), deberán también ofrecer al prestatario información precontractual personalizada -una vez que el prestatario haya informado al prestamista sobre sus circunstancias- a efectos de poder comparar con otras entidades. La información personalizada se proporcionará a través de la Ficha Europea de Información Normalizada

13 Art. $61.2^{\circ}$. "Las entidades declarantes y los intermediarios de crédito inmobiliario, tendrán derecho a obtener informes sobre los riesgos de las personas físicas o jurídicas, incluidas las Administraciones públicas, registrados en la CIR, siempre que dichas personas cumplan alguna de las circunstancias siguientes:

a) Mantener con la entidad algún tipo de riesgo.

b) Haber solicitado a la entidad un préstamo o cualquier otra operación de riesgo.

c) Figurar como obligadas al pago o garantes en documentos cambiarios o de crédito cuya adquisición o negociación haya sido solicitada a la entidad.

Las entidades deberán informar por escrito a las personas en las que concurra el supuesto contemplado por la letra b) precedente del derecho de la entidad previsto en este apartado.

Las entidades conservarán los documentos justificativos de las solicitudes a que se refieren las letras b) y c) precedentes que hayan sido denegadas durante el plazo establecido con carácter general en el artículo 30 del Código de Comercio.

El Banco de España podrá impedir temporalmente el acceso de una entidad declarante a los datos de la CIR cuando haya incumplido sus obligaciones de información con la calidad y exactitud necesarias a juicio del Banco de España”. 
(FEIN), cuyo contenido viene descrito en el Anexo 1 de la Ley. Esta ficha tiene la consideración de oferta vinculante (art. 14.1. a) y deber ser proporcionada con al menos 10 días de antelación al momento en que el prestatario pueda quedar vinculado (Art. 10). Asimismo, se le proporcionará una Ficha de Advertencias Estandarizadas (FiAE) ${ }^{14}$.

El artículo 14 describe otros datos que habrán de comunicarse al posible prestatario. La gran mayoría son reiteración del contenido mínimo que establece la FEIN, como distintos escenarios en caso de posible pacto de intereses variables o los gastos atribuidos a cada una de las partes (esencialmente son atribuidos al prestamista salvo la valoración del inmueble, que se atribuye al prestatario y los impuestos, que se remite a las normas tributarias.). Como novedoso, obliga este artículo a entregar copia del proyecto de contrato al prestatario.

Aparte de toda la información y documentación que debe ponerse a disposición del cliente, se debe advertir al mismo que tiene que acudir al notario de su elección para recibir asesoramiento personalizado antes de la firma del contrato. Esta reunión informativa con el notario no es potestativa para el prestatario, sino que se configura como un deber, deber que se extiende a los fiadores y titulares de la garantía. El prestamista debe remitir por medios telemáticos seguros al notario elegido la documentación proporcionada al prestatario. Ante el notario, aparte de

14 A propósito de esta segunda ficha, Ángel Carrasco comenta: "De manera suficientemente expresada, aunque no articulada como objetivo fundamental, la Directiva quería conseguir una suerte de mercado hipotecario uniforme con consumidores en Europa. En una de sus pocas normas de máxima armonización, prohibió que los Estados introdujeran variaciones en la Ficha Europea de Información Normalizada (FEIN). Pero a los gobiernos españoles no les basta con la «transparencia de baja intensidad» y quieren una transparencia reforzada, recordando lo que aquí pasó (pero sólo aquí) con la cláusula suelo. Más como no pueden modificar la FEIN, simplemente, e ingeniosamente, crean una segunda ficha complementaria que los prestamistas han de entregar (la FiAE, made in Spain), con lo que el resultado es el mismo que se quería prohibir por la Directiva, aunque la misma Directiva, ingenuamente, da por bueno este procedimiento elusivo. De momento, un préstamo inmobiliario al consumo concertado en un Estado miembro distinto de España no podrá producir en España el efecto de transparencia material si el consumidor es residente en España o la finca está sita en España. De hecho, no será ni siquiera inscrito, si es un préstamo hipotecario"; Ángel Carrasco Perera, "Dos datos sabrosos sobre las «Fichas de información» de la Ley de Contratos de Crédito Inmobiliario", Gómez-Acebo\& Pombo Publicaciones, acceso el 1 de abril de 2019, https://www.ga-p.com/publicaciones/dos-datos-sabrosos-sobre-las-fichas-de-informacionde-la-ley-de-contratos-de-credito-inmobiliario/. 
solventar cualquier duda que la documentación proporcionada por el acreedor le haya podido quedar irresuelta, deberá responder a un test que versará a cerca de la documentación entregada al mismo y la información que se le ha suministrado.

Este test, cuyo contenido no está descrito en la ley, entendemos que debe tratar, al menos, sobre el contenido típico del contrato, por lo que va a constituir un impedimento para la posible futura oposición a la ejecución en caso de producirse la misma, dado que el notario tiene la obligación de hacer hincapié en cada una de las cláusulas de los dos ficheros comentados "con referencia expresa a cada una".

Producida la comparecencia del cliente ante el notario éste deberá levantar un Acta previa a la firma de la escritura en la que se hará constar el cumplimiento de los plazos establecidos en la ley (mínimo 10 días desde la entrega de la documentación a la firma del contrato), el asesoramiento que se le ha prestado al prestatario, que se le ha prestado información individualizada sobre las cláusulas que constan en las fichas preceptivas (FEIN y FiAE) y que el cliente ha realizado el test previsto. Si el contenido de dicho Acta es negativo, por incomparecencia del prestatario, no se podrá firmar el préstamo. Tampoco podrá otorgar escritura de préstamo el notario si no se hubiere otorgado dicha Acta (art. 22.2), ni inscribir el Registrador escritura en la que no conste la alusión al otorgamiento de este Acta.

El asesoramiento del notario no exime al prestamista de cumplir sus obligaciones de información conforme al art. 14. 2 (art. 15.9), por lo que es previsible que las entidades crediticias acaben implantando algún documento similar al test a realizar por el notario para acreditar el cumplimiento de sus obligaciones en este sentido.

La información precontractual deberá ser conservada por el prestamista durante mínimo 6 años tras la cesación de los efectos del contrato. Transcurrido este plazo, deberá ponerla a disposición del prestatario (D.A. $4^{\mathrm{a}}$ ). 


\subsection{LA FICHA EUROPEA DE INFORMACIÓN NORMALIZADA (FEIN)}

Uno los objetivos que la Directiva Europea que se traspone perseguía era obtener la máxima armonización entre los estados miembros en lo referente a la información precontractual, con la finalidad de crear un verdadero mercado interior con un grado equivalente de protección de los consumidores. Para ello, crea una ficha de información que debe ser adoptada por los estados miembros sin alteraciones ${ }^{15}$, salvo que dichas modificaciones, que sólo se permiten en las instrucciones para rellenar la ficha, conlleven unas medidas de protección más rigurosas. El contenido de la ficha debe constar en un único documento, sin perjuicio del resto de documentación que establezca cada Estado, que obligatoriamente deberá constar en documento aparte. La Ley prohíbe a las comunidades autónomas modificar, en el ejercicio de sus competencias, la información precontractual establecida en la ficha ${ }^{16}$.

La ficha contiene una información detallada del producto que se ofrece y está adaptada los datos que han sido suministrados por el posible cliente. Existe algunas pequeñas contradicciones entre lo que viene recogido en la ficha -que no puede ser modificado por los estados miembros-, y la regulación que contiene la Ley, como por ejemplo, la declaración que hace la introducción de que la emisión de la ficha no obliga a la entidad a conceder el préstamo, cuando la Ley establece que la ficha tendrá el carácter de oferta vinculante para la entidad (a diferencia de lo que

15 El esquema de la ficha es el siguiente:

Texto introductorio. 1. Prestamista.2. Intermediario de crédito. 3. Características principales del préstamo. 4. Tipo de interés y otros gastos. 5. Periodicidad y número de pagos.6. Importe de cada cuota. 7. Tabla ilustrativa de reembolso. 8. Otras obligaciones. 9. Reembolso anticipado. 10. Elementos de flexibilidad. 11. Otros derechos del prestatario. 12. Reclamaciones. 13. Incumplimiento de los compromisos vinculados al préstamo: consecuencias para el prestatario. 14. Información adicional. 15. Supervisor.

16 Disposición adicional quinta. Desarrollo autonómico. Sin perjuicio del desarrollo de la legislación básica estatal que realicen las Comunidades Autónomas en el ejercicio de las competencias asumidas estatutariamente, la información precontractual a facilitar a los prestatarios debe ser homogénea, en aras de la unidad de mercado, de tal forma que puedan valorar adecuadamente las diferencias entre unas ofertas y otras en todo el territorio español, por lo que la normativa autonómica deberá respetar los modelos normalizados de información que se establezcan por la normativa básica, y no podrá exigir adicionar documentación complementaria que pueda producir confusión en el prestatario y distorsione el objeto de la normativa básica de transparencia. 
sucedía con la anterior ficha de información personalizada -FIPER-, establecida por la Orden EHA 2899/2011, de 28 de octubre, de transparencia y protección del cliente de servicios bancarios (BOE núm. 261 de 29 de octubre de 2011) que no era, en principio, vinculante).

La ficha, como oferta vinculante para el prestamista, es esencialmente temporal. Lo contrario llevaría a entenderle obligado sin plazo a unas condiciones que han podido variar por el transcurso del tiempo. Por ello, la misma ficha debe establecer un plazo de validez que no puede ser, según la Ley, inferior a 10 días. Las instrucciones para rellenar la ficha la colocan en el texto introductorio e indican que "la fecha de validez figurará debidamente destacada. A los efectos de esta sección, se entiende por «fecha de validez» el plazo hasta el cual la información contenida en la FEIN, el tipo de interés, por ejemplo, se mantendrá inalterada y será de aplicación en caso de que el prestamista decida otorgar el crédito dentro de ese plazo".

El incorporar las ofertas de las diferentes entidades en una ficha igual facilita al prestatario la comparación entre todas ellas haciendo más fácil la adopción de una decisión, en primer lugar, sobre la misma contratación y, en su caso, sobre cuál de los préstamos le resulta más conveniente o se ajusta mejor a sus necesidades-deseos.

\subsection{TASACIÓN DE LOS BIENES INMUEBLES}

La ley contempla la obligatoriedad de la tasación de las garantías aportadas por sociedad independiente, aunque no se pacte la ejecución hipotecaria o la venta extrajudicial. Es uno de los gastos que el prestatario debe asumir por Ley (Art. 14.1.e) i.)

A este tenor, la DA $10^{\mathrm{a}}$ se remite a la aprobación, en el plazo de 6 meses desde la entrada en vigor de la Ley, de una norma que regule la homologación de profesionales-tasadores a efectos de la Ley. Además, y 
en el mismo plazo, evaluará la conveniencia de modificar las actuales normas de valoración de inmuebles.

Por su parte, la DA $1^{\text {a }}$ modifica el artículo 129 de la Ley Hipotecaria (LH) elevando de $75 \%$ al $100 \%$ del valor de tasación requerido como tipo para la subasta en la ejecución notarial y estableciendo que, en ningún caso, podrá ser inferior al establecido como valor de tasación a efectos de subasta en el procedimiento judicial. El problema surgirá cuando, usando de la facultad que contempla el artículo 682 de la Ley 1/200o. De 7 de enero de Enjuiciamiento Civil -LEC- (BOE núm. 7, de 8 de enero de 2000), los interesados hayan tasado la finca en una cantidad comprendida entre el 75\% y el 99 \% del valor de tasación a efectos de subasta judicial. En este supuesto, se deberá renunciar a la ejecución notarial, ya que no puede cumplir las dos condiciones que ha introducido la Ley, a saber, que el tipo para subasta notarial sea el 100\% del valor de tasación y que este tipo sea idéntico al pactado para la ejecución judicial.

\section{CONTENIDO DEL CONTRATO}

La Ley regula prácticas crediticias y cláusulas contractuales que ha estado en el punto de mira de nuestros tribunales en los últimos años, en relación con la protección del consumidor.

\subsection{LAS VENTAS VINCULADAS}

Respecto a la oferta de préstamos, la ley prohíbe (art. 17), en general, las ventas vinculadas -no así la ventas combinadas-; aunque excepciona aquellas que hayan sido autorizadas por la autoridad competente -previo informe del Banco de España u otro organismo consultivo por su ámbito de competencia- por acarrear un claro beneficio a los prestatarios.

También se autoriza la imposición de la obligación de suscribir un seguro para cubrir el incumplimiento de las obligaciones establecidas en 
el préstamo o del seguro de daños en el inmueble cuando se trate de un préstamo hipotecario, pero en ambos casos el prestatario podrá elegir a un proveedor del seguro distinto del prestamista quien no podrá rechazar el seguro si las prestaciones del tercero se ajustan a lo que él mismo hubiera propuesto al prestatario.

Critica la doctrina la falta de rigor al incluir la obligación de suscripción de un contrato de seguro "con obligación de aceptar pólizas alternativas” como una venta vinculada, cuando por su caracterización debiera haberse incluido en el concepto de venta combinada, sí admitida por la Ley. Si la finalidad era impedir la modificación de las condiciones del préstamo o, en su caso y como contempla la Ley, el cobro de cargos adicionales por el análisis de las pólizas alternativas, se podría haber establecido expresamente. "Se llega al absurdo de entender como excepción a la prohibición de ventas vinculadas, la admisión de ciertas ventas vinculadas cuando dejen de ser vinculadas" $" 17$.

Por último, se admite la vinculación del préstamo a la adquisición de ciertos productos financieros -parece ser que públicos: "Establecidos por orden de la persona titular del Ministerio de Economía y Empresa”- por parte del prestamista o sus familiares cercanos con la finalidad de servir de garantías del préstamo.

Cuando la oferta crediticia de la entidad contenga alguna de estas manifestaciones, La FEIN deberá advertirlo (en su sección $8^{\text {a }}$ "otras obligaciones”), indicando las características mínimas que deba tener el producto de otra entidad para ser aceptado por el prestamista y de los efectos económicos de la cancelación separada del préstamo o de los otros productos contratados sobre el coste conjunto, si se admite.

17 Covadonga Díaz Llavona, "Ley de Contratos de Crédito Inmobiliario, ¿cambará algo para la distribución banco-aseguradora?”, Diario LA LEY 9387 (2019): 5. 


\subsection{PRÉSTAMOS EN DIVISA EXTRANJERA}

Si el préstamo se va a verificar en moneda extranjera, la FEIN debe contener obligatoriamente una serie de disposiciones relativas a esta modalidad contractual, dentro de su apartado 3, relativo a las "características del contrato":

- Que el prestatario recibirá comunicaciones periódicas o advertencias mínimo cuando el préstamo haya sufrido una fluctuación superior al $20 \%$, informando de la facultad de cambiar de divisa.

- El aumento que puede experimentar el préstamo si la divisa nacional -euro- disminuye su valor respecto de la divisa del préstamo en, al menos, un 20\%.

- Importe máximo que deba reembolsar el prestatario, si se ha pactado algún tipo de mecanismo para limitar los posibles efectos perjudiciales de las modificaciones del tipo de cambio en las monedas que intervienen en el contrato.

En cumplimiento de las anteriores estipulaciones contenidas en la ficha, el art. 20 de la Ley reconoce el derecho del prestatario de modificar el préstamo a una moneda alternativa y regula el deber del prestamista de informar periódicamente -en los términos y plazos que se establezcan por el Ministerio de Economía- al prestatario del incremento que se haya producido en el préstamo por las modificaciones del tipo de cambio. Esta notificación se realizará, en todo caso, si el importe adeudado por el prestatario sufriera un incremento de más del $20 \%$ respecto del importe que se debería si se aplicase el cambio vigente a fecha de celebración del contrato.

El incumplimiento de las obligaciones establecidas en el art. 20 determinará, en favor del prestatario consumidor, la nulidad de la cláusula multidivisa, permitiendo al prestatario solicitar la modificación del contrato como si el mismo se hubiera pactado en su moneda desde el inicio. 


\subsection{TIPO DE INTERÉS REMUNERATORIO}

Respecto del tipo de interés pactado en el contrato (art. 21), se prohíbe la modificación del mismo constante el contrato en perjuicio del prestatario, salvo acuerdo recogido por escrito. En caso de modificación del mismo, la variación del coste del préstamo se deberá ajustar a un índice de referencia objetivo.

El artículo 14 obliga a incluir en la FiAE una explicación a "los índices oficiales de referencia utilizados para fijar el tipo de interés aplicable”.

Si se pacta un tipo de interés variable, el tipo de referencia deberá ser claro, objetivo y fácilmente verificable por las partes del contrato y por las autoridades. Además, deberá constar en documento separado, dentro de la información contractual personalizada que se facilita al posible prestatario, una referencia especial a las cuotas periódicas a satisfacer por el prestatario en diferentes escenarios de evolución de los tipos de interés (Art. 14.1.c.). El tipo de interés no debe ser susceptible de influencia por el propio prestamista y los datos que configuren dicho tipo deben resultado de un procedimiento matemático objetivo.

Se prohíbe la llamada "cláusula suelo" y excluye la aplicación de un interés negativo, terminando con la duda sobre la legalidad de la cláusula inserta en los contratos, en esta última época de EURIBOR negativo, de prohibir la liquidación de intereses negativos.

\subsection{AMORTIZACIÓN ANTICIPADA A VOLUNTAD DEL PRESTATARIO}

La Ley también regula el reembolso o amortización anticipada parcial o total de la deuda por voluntad del prestatario, que se caracteriza como un derecho ejercitable en cualquier momento de la vida del préstamo, estableciendo como único requisito cumplir un plazo de preaviso a pactar que, en cualquier caso, no puede ser superior a un mes. Cuando el prestatario comunica al prestamista su intención de amortizar anticipadamente parte o el total de la deuda, éste debe, en el plazo de 3 días, 
facilitarle la información necesaria para que el cliente pueda sopesar las consecuencias económicas de tal decisión. En caso de inclinarse por la amortización, el prestatario tiene derecho a la reducción de los costes del préstamo proporcionales al tiempo que faltase para su vencimiento natural y a la cancelación de los contratos de seguro accesorios, con devolución de la parte proporcional de la prima, salvo que manifestase expresamente su deseo de continuar con los mismos.

Por su parte, se podrá pactar en el contrato una compensación para el prestamista en caso de ejercicio de este derecho de reembolso anticipado, pero esta compensación-comisión, que se concreta en "importe de la pérdida financiera que pudiera sufrir el prestamista" ${ }^{18}$ no podrá superar ciertos límites, que varían según el tipo de interés fijo o variable pactado en el contrato y el tiempo que haya transcurrido desde su constitución.

Si el tipo de interés pactado fue variable y el reembolso anticipado se produce en los primeros 3 años de vida del préstamo, la compensación no podrá superar el o,25\% del capital reembolsado, mientras que si el reembolso se produce en los 5 primeros años el porcentaje se reduce al $0,15 \%$.

En caso de modificación posterior del tipo de interés a fijo, o de subrogación de un nuevo acreedor con cambio de interés a fijo, la comisión por reembolso anticipado no podrá superar el o,15\% si se produce en los 3 primeros años de vida del préstamo y no podrá exigirse ningún tipo de

18 Art. 23.8: La pérdida financiera sufrida por el prestamista (...) se calculará, proporcionalmente al capital reembolsado, por diferencia negativa entre el capital pendiente en el momento del reembolso anticipado y el valor presente de mercado del préstamo.

El valor presente de mercado del préstamo se calculará como la suma del valor actual de las cuotas pendientes de pago hasta la siguiente revisión del tipo de interés y del valor actual del capital pendiente que quedaría en el momento de la revisión de no producirse la cancelación anticipada. El tipo de interés de actualización será el de mercado aplicable al plazo restante hasta la siguiente revisión. 
comisión si ya han transcurrido esos 3 años (art. 23.6). La Ley pretende favorecer la conversión de los contratos a interés fijo ${ }^{19}$.

Si el tipo de interés pactado fuera fijo, la comisión no podrá superar el $2 \%$ de la cantidad amortizada, si se produce durante los 10 primeros años del préstamo o del 1,5 \% si se produce en cualquier momento posterior.

\subsection{VENCIMIENTO ANTICIPADO DEL PRÉSTAMO POR INCUMPLIMIENTO}

El artículo 24 de la ley regula el vencimiento anticipado del préstamo por impago del capital del préstamo o de sus intereses, y llaman la atención dos cuestiones. En primer lugar, que en este epígrafe la ley no mencione expresamente la condición de consumidor que debe concurrir en el prestatario cuando el contrato tenga por objeto "adquirir o conservar derechos de propiedad”, tal y como menciona el artículo 2.1.b) de la ley, y tampoco lo haga al introducir en la Ley Hipotecaria (aprobada su redacción por Decreto de 8 de febrero de 1946, BOE núm. 58 de 27 de febrero de 1946) un nuevo art. 129 bis con el mismo contenido que este artículo (Disposición Final $1^{\text {a }}$ Cuatro). En segundo lugar, que el vencimiento anticipado se configure como una consecuencia legal si concurren los requisitos, y no como un posible pacto a introducir en el contrato. En su epígrafe segundo manifiesta que no se admitirá pacto en contrario $^{20}$.

19 La Exposición de Motivos lo explica así: "Igualmente reseñable es la opción de favorecer la subrogación y la novación modificativa de préstamos cuando tengan por finalidad la modificación del tipo de interés variable a uno fijo. El objetivo perseguido es lograr que los prestatarios puedan conocer con exactitud el coste que en el medio y largo plazo les va a suponer la financiación que contratan, lo que les permitirá realizar una planificación financiera a largo plazo, a la par que favorece la simplicidad en la redacción de los contratos y en consecuencia la transparencia con los prestatarios. En todo caso, la regulación trata de establecer un punto de equilibrio entre facilitar a las personas físicas el reembolso de sus préstamos y no generar escenarios adversos en los prestamistas respecto de la oferta de contratos de préstamo a tipo fijo, en los que el riesgo de tipo de interés es mayor".

20 "El legislador opera como si modificara ex lege los contratos anteriores, de forma que quedan suprimidas las cláusulas (presumiblemente) negras que contenían y sustituidas por las del artículo 24, que se supone que "pasan el corte» de validez". Ángel Carrasco Perera: "Vencimientos anticipados del crédito hipotecario a partir del 16 de junio de este año", Gomez Acedo\&Pombo 
Las condiciones que impone la ley para que se produzca el vencimiento anticipado son: La existencia de mora en el pago, tanto de capital como de intereses; cualificación del retraso en el pago, que veremos a continuación y requerimiento de pago al prestatario dando plazo para su cumplimiento -mínimo un mes- y con advertencia de que su incumplimiento dará lugar a la reclamación de la totalidad de las cantidades adeudadas, perdiendo el beneficio de plazo.

En cuanto a la gravedad del incumplimiento que puede dar lugar al vencimiento anticipado depende del momento de la vida del préstamo en el que nos encontremos. Si el incumplimiento se produce en la primera mitad de vida del préstamo, se requerirá que la cuantía de las cuotas vencidas y no satisfechas equivalgan al 3\% del capital del préstamo o equivalgan al impago de 12 plazos mensuales o el número de cuotas -si no son mensuales- que equivalgan a un incumplimiento de la obligación de pago por un plazo equivalente a 12 meses.

Si el incumplimiento se produce en la segunda mitad del préstamo, se requerirá que la cuantía de las cuotas vencidas y no satisfechas equivalgan al 7\% del capital del préstamo o equivalgan al impago de 15 plazos mensuales o el número de cuotas tal -si no son mensuales- que equivalgan a un incumplimiento de la obligación de pago por un plazo equivalente a 15 meses.

\subsection{INTERÉS DE DEMORA}

El tipo de interés de demora aplicable a los préstamos o créditos hipotecarios concluidos por persona física y que estén garantizados mediante hipoteca de bienes muebles de uso residencial será el interés remuneratorio pactado elevado en 3 puntos y sólo se devengará sobre el capital vencido y pendiente de pago, no pudiendo ser capitalizados.

Publicaciones, acceso el 8 de abril de 2019, https://www.ga-p.com/publicaciones/vencimientosanticipados-del-credito-hipotecario-a-partir-del-16-de-junio-de-este-ano/ 
El legislador se apartó del criterio contenido en el proyecto de ley, de establecer como interés de demora el incluido en la Ley Hipotecaria por la Ley 1/2013, de 14 de mayo, de medidas para reforzar la protección a los deudores hipotecarios, reestructuración de deuda y alquiler social (BOE núm. 116, de 15 de mayo de 2013) consistente en aplicar el triple del interés legal del dinero; en consonancia con la última doctrina del Tribunal Supremo, que había establecido el límite en el interés remuneratorio más dos puntos. Finalmente ha optado por un tipo de interés determinado o fijo, en cuando no establece un máximo con una posible horquilla en cuyos extremos debe "colocarse" el interés pactado en el contrato para ser válido -lo que igualmente acarreaba solicitudes de nulidad de la cláusula-, sino que el tipo de interés es el que establece la ley, y no hay posibilidad de modificarlo.

$\mathrm{Al}$ igual que sucede con el vencimiento anticipado, tampoco se admite pacto en contrario, por lo que estamos ante un interés de demora "legal" o por imperativo legal. La E. M. de la Ley justifica ambas medidas: "Se persigue impedir la inclusión en el contrato de cláusulas que pudieran ser abusivas y, a la vez, robustecer el necesario equilibrio económico y financiero entre las partes”.

\section{LA SUBROGACIÓN EN EL PRÉSTAMO}

Para concluir, nos resta poner de manifiesto otra modificación en el régimen de la hipoteca, en fase de ejecución del contrato, que favorece la

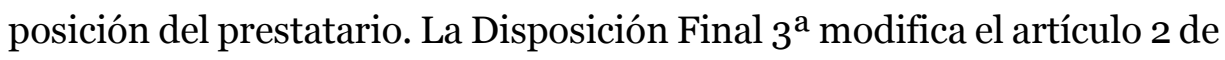
la Ley 2/1994, de 30 de, de subrogación y modificación de préstamos hipotecarios marzo (BOE núm. 80, de 4 de abril de 1994), el cual permitía que la prestamista originaria pudiera paralizar la "fuga" del préstamo a otra entidad con tal de que, al menos, igualase la oferta realizada por la entidad a la que el prestatario pretendía trasladar su préstamo. La modificación consiste en que se elimina la posibilidad de que la entidad 
prestamista subrogada pueda enervar la subrogación, aunque iguale o mejore las condiciones de la prestamista subrogante, dependiendo exclusivamente del prestatario la decisión de quedarse en la actual entidad o traspasar el préstamo a la nueva.

Esta facilidad concedida al prestatario permite al mismo eludir el plazo mínimo de 3 años establecido en la $693.3^{\circ}$ LEC para volver a enervar la ejecución del inmueble-vivienda habitual frente al acreedor. Entiendo que, modificada la entidad crediticia, habría un "borrón y cuenta nueva" en lo que se refiere a los plazos, ya que una nueva "liberación" del bien se produciría frente a otro acreedor.

\section{CONCLUSIONES}

La Ley da cumplimiento -parcial- al deber de transposición de la Directiva e introduce nuevas garantías para la protección de los contratantes de créditos que se traducen, sobre todo, en un refuerzo de los deberes de asesoramiento e información y en un agravamiento de la obligación de comprobar la solvencia del prestatario, fomentando los créditos responsables.

Por otra parte, y tras la lectura de la misma, permanece la impresión de que, a su vez, se ha intentado "solucionar" o quitarse de en medio el problema de las masivas solicitudes de declaración de nulidad de determinadas cláusulas insertas en los préstamos hipotecarios ya celebrados, que a su vez han dado lugar a cuestiones prejudiciales que han terminado con sentencias del Tribunal de Justicia de la UE que, la mayoría de las veces, han puesto en entredicho la protección dispensada al consumidor.

Como ejemplo, la disposición transitoria primera de la Ley declara la no aplicación de la misma a los contratos celebrados con anterioridad a su entrada en vigor; pero a continuación establece la excepción a la irretroactividad respecto de la cláusula de vencimiento anticipado cuyas reglas, establecidas en el artículo 24 de la ley les serán de aplicación 
siempre que no se hubiera declarado ya su vencimiento anticipado. Y la reciente Sentencia de TJUE, de 26 de marzo de 2019 (ECLI:EU:C: 2019:250), acaba de declarar la no integración por el Juez de esta cláusula y su exclusión del contrato cuando pueda persistir sin la misma que puede- y salvo que el "consumidor" quiera renunciar a su nulidad por serle más favorable. Si no se verifica esta renuncia, al prestamista no le queda otra que iniciar un procedimiento declarativo, apoyado en el artículo 1124 del Código civil (Real Decreto de 24 de julio de 1889, publicado en la Gaceta de Madrid con fecha 25 de julio de 1889)-, solicitando la resolución por incumplimiento, procedimiento que demora la satisfacción de las pretensiones del prestamista frente al prestatario incumplidor. Pues bien, aquellos contratos que no hayan sido declarados vencidos anticipadamente van a poder "eludir" en el futuro lo que hubiera sido la más que probable oposición a la ejecución por parte del prestatario, con pretensión de declaración de nulidad de la cláusula de vencimiento anticipado por abusiva o por falta de transparencia de la misma.

También la obligación de documentar, mediante un Acta notarial con su presunción de certeza-, el cumplimiento de los deberes de asesoramiento e información, Acta en la cual el notario debe hacer constar que se le ha proporcionado correctamente al prestatario toda la documentación precontractual requerida en la ley, que comprende las cláusulas individuales incluidas en el FEIN y que ha superado un test sobre las mismas, va a hacer muy difícil que pueda declararse con posterioridad la falta de transparencia de las cláusulas insertas en el contrato.

En fin, la ley deja una sensación agridulce: mejora la posición del prestatario en cuanto a la información y asesoramiento que se le debe prestar y a la determinación imperativa por la ley de las cláusulas contractuales que más problemas han venido dando en relación a su posible carácter abusivo, pero da la sensación que se ha quedado corta. Habrá que esperar a los numerosos desarrollos que anuncia la Ley para tener una visión completa de la reforma operada. 


\section{REFERENCIAS BIBLIOGRÁFICAS}

Ballugera Gómez, Carlos. "Control de transparencia registral de la hipoteca, Registro de Condiciones Generales de la Contratación y Registro de la Propiedad”. En Especial Ley Reguladora de los Contratos de Crédito Inmobiliario. Las Rozas, Madrid: Wolters Kluwer, 2019.

-. "Anotaciones de un notario perplejo al Anteproyecto de Ley Reguladora de los Contratos de Crédito Inmobiliario”. Diario La Ley, 9047 (2017).

Cabanas Trejo, Ricardo. "La nueva Ley reguladora de los Contratos de Crédito Inmobiliario”. en Diario La Ley, 9379 (2019).

Carrasco Perera, Ángel. "Dos datos sabrosos sobre las «Fichas de información» de la Ley de Contratos de Crédito Inmobiliario”, GómezAcebo\& Pombo Publicaciones. Acceso el 1 de abril de 2019, https://www.ga-p.com/publicaciones/dos-datos-sabrosos-sobrelas-fichas-de-informacion-de-la-ley-de-contratos-de-credito-inmobiliario/.

-. "Vencimientos anticipados del crédito hipotecario a partir del 16 de junio de este año", Gomez Acedo\&Pombo Publicaciones. Acceso 8 de abril de 2019, https://www.ga-p.com/publicaciones/vencimientosanticipados-del-credito-hipotecario-a-partir-del-16-de-junio-deeste-ano/.

Cuena Casas, Matilde. "Préstamo responsable y datos de solvencia patrimonial en la Ley Reguladora de los Contratos de Crédito Inmobiliario”. Actualidad Civil 9 (2019).

Díaz Llavona, Covadonga. "Ley de Contratos de Crédito Inmobiliario, ¿cambiará algo para la distribución banco-aseguradora?”. Diario La Ley 9387 (2019).

Díez de Los Ríos Flores, Miguel. "La Ficha Europea del Crédito Hipotecario (FEIN)”. En El préstamo hipotecario y el mercado de crédito 
en la Unión Europea, dirigido por María De La Sierra Flores Doña, 379-404. Madrid: Dykinson, 2016.

Moya Fernández, Antonio, José Javier Villanueva Redondo y Javier Colino Sánchez-Ventura. "El Proyecto de Ley reguladora de los contratos de crédito inmobiliario. Actualidad Jurídica Uría Menéndez 48 (2018): 102-117. https://www.uria.com/documentos/publicaciones/5806/documento/foro_esp_05.pdf?id=7882

María Sandra Velázquez Vioque Ilustre Colegio de Abogados de Cáceres Av. Virgen de la Montaña, 6 10002 Cáceres (España) sanvelvio@gmail.com 